\title{
Cardiovascular magnetic resonance imaging of coronary atherothrombosis
}

\author{
W. Yong Kim, MD, PhD, ${ }^{\mathrm{a}, \mathrm{b}}$ Elmar Spuentrup, $\mathrm{MD},{ }^{\mathrm{c}}$ Arno Buecker, $\mathrm{MD},{ }^{\mathrm{c}}$ \\ Warren J. Manning, MD, ${ }^{\mathrm{d}, \mathrm{e}}$ and René $M$. Botnar, $\mathrm{PhD}^{\mathrm{d}, \mathrm{f}}$
}

\section{INTRODUCTION}

Cardiovascular disease remains the leading cause of morbidity and death in the Western world and is rapidly becoming the number one killer in the developing countries. ${ }^{1}$ Atherothrombosis, characterized as atherosclerotic plaque disruption with superimposed thrombosis, is the most important cause of acute coronary syndromes and cardiovascular death. ${ }^{2-4}$ The underlying pathology of most acute coronary syndromes involves coronary atherosclerosis with ruptured plaques, followed by acute occlusive or subocclusive thrombus formation. $^{2-4}$ The term vulnerable plaque has been introduced to identify thrombosis-prone plaques and plaques with a high probability of undergoing rapid progression, thus becoming culprit plaques. Recently, the term vulnerable patient has been suggested in recognition of contributing culprit factors including vulnerable blood (prone to thrombosis) and vulnerable myocardium (prone to fatal arrhythmia) that identify patients with a high likelihood of having cardiac events develop in the near future. ${ }^{5}$

Investigators have shown multiple rupture-prone or ruptured plaques in a wide range of cardiovascular patient populations. ${ }^{6-11}$ As a result, the concept of pan-coronary vulnerability has been introduced to emphasize the importance of going beyond a single vulnerable plaque and evaluating the total arterial tree as a whole. ${ }^{12-14}$

Noninvasive visualization of evolving arterial thrombus would facilitate detection of thrombosis burden in patients with acute coronary syndrome. Similarly, noninvasive imaging techniques may enhance our cur-

From the aMR-Center, Institute of Clinical Medicine, and ${ }^{\mathrm{b}}$ Department of Cardiology, Aarhus University Hospital, Skejby Sygehus, Aarhus, Denmark, 'Department of Diagnostic Radiology, Aachen Technical University, Aachen, Germany, Departments of Medicine (Cardiovascular Division) $^{\mathrm{d}}$ and Radiology, ${ }^{\mathrm{e}}$ Beth Israel Deaconess Medical Center and Harvard Medical School, Boston, Mass, and Department of Nuclear Medicine, Technical University Munich, Munich, Germany. ${ }^{\mathrm{f}}$

Reprint requests: Won Yong Kim, MD, MR-center and Department of Cardiology, Skejby University Hospital, 8200 Aarhus N, Denmark; yong.kim@ki.au.dk.

J Nucl Cardiol 2005;12:337-44.

$1071-3581 / \$ 30.00$

Copyright $\odot 2005$ by the American Society of Nuclear Cardiology.

doi:10.1016/j.nuclcard.2005.03.007 rent understanding of the natural history and of the pathophysiologic mechanisms of atherothrombosis. Arterial thrombi are not reliably detected by current diagnostic techniques. Intravascular ultrasound and angiography are invasive and use indirect and nonsensitive criteria for thrombus detection. Angioscopy is highly invasive and not widely available. ${ }^{15}$ Among the different imaging modalities, cardiovascular magnetic resonance (CMR) is emerging as the most comprehensive noninvasive in vivo imaging modality for atherothrombosis. ${ }^{16-18}$

In this review we will address the current and evolving developments in CMR with a focus on coronary plaque imaging and in vivo molecular imaging of coronary thrombosis. With further development, CMR imaging of atherothrombosis in the diseased vessel walls (carotid arteries, thoracic and abdominal aorta, and coronary arteries) may prove to be clinically beneficial in identifying vulnerable patients.

\section{DIAGNOSIS OF VULNERABLE PLAQUES}

On the basis of autopsy studies, a number of major and minor criteria for defining vulnerable plaques have been proposed. ${ }^{5}$ These criteria of vulnerability (Tables 1 and 2) include morphologic features (eg, size of lipid core and thickness of fibrous cap), as well as markers of plaque activity (eg, plaque inflammation, superficial platelet aggregation, and fibrin deposition). Most of the proposed features of plaque vulnerability are based on cross-sectional and retrospective studies of culprit lesions. Noninvasive surrogate markers, such as coronary vessel wall thickness and plaque burden, together with markers of plaque activity, may supplement or improve cardiovascular risk stratification especially in patients with an intermediate cardiovascular risk. Noninvasive imaging techniques provide a mechanism for prospective outcome studies to determine whether identifying asymptomatic vulnerable patients may allow for therapeutic interventions to reduce clinical cardiovascular events.

\section{CMR CORONARY ARTERY IMAGING}

Recently, the accuracy of coronary magnetic resonance imaging (MRI) was investigated among patients 
Table 1. Criteria for defining vulnerable plaque, based on the study of culprit plaques

\author{
Major criteria \\ Active inflammation (monocyte/macrophage $+/-$ \\ T-cell infiltration) \\ Thin fibrous cap with large lipid core \\ Endothelial denudation with superficial platelet \\ aggregation \\ Fissured plaque \\ Diameter stenosis $>90 \%$ \\ Minor criteria \\ Superficial calcified nodule \\ Glistening yellow \\ Intraplaque hemorrhage \\ Endothelial dysfunction \\ Outward (positive) remodeling (Glagov effect)
}

Modified from Naghavi et al. ${ }^{5}$

with suspected coronary disease in a prospective multicenter study. ${ }^{19}$ Overall, coronary MRI had an accuracy of $72 \%$ (95\% confidence interval, 63\%-81\%) in diagnosing coronary artery disease (CAD) (defined as $\geq 50 \%$ diameter reduction on x-ray angiography). ${ }^{19}$ Coronary MRI was particularly helpful for excluding left main coronary artery or 3-vessel disease, with a negative predictive value of $100 \% .^{19}$

However, coronary MRI remains technically demanding, as respiratory and cardiac motion limits the useful data acquisition window. Imaging the walls of coronary vessels is particularly challenging because of their wall thickness $(0.5-2 \mathrm{~mm})$, tortuous 3-dimensional (3D) course of the coronary vessels, and close proximity to epicardial fat, coronary blood, and myocardium. Motion compensation strategies for coronary vessel wall imaging are therefore even more stringent than for "lumen" coronary MRI. Technical solutions to meet the challenges of coronary vessel wall imaging have been developed, allowing more consistent visualization of the proximal and mid portions of the native coronary vessel walls.

\section{CARDIAC MOTION}

Because of the rapid intrinsic cardiac motion during the cardiac cycle, synchronization of data acquisition to the electrocardiogram is mandatory. A short cardiac acquisition window of less than $10 \%$ of the cardiac cycle in either end systole or mid diastole (periods of relative myocardial diastasis) with a well-defined delay to the $\mathrm{R}$ wave is typically used for data acquisition. ${ }^{20,21}$ These measures are essential to avoid cardiac motion-induced artifacts but reduce the scan efficiency by a large scale.
Subject-specific mid-diastolic acquisition usually provides the most optimal imaging in subjects with a heart rate lower than 80 beats/min. For subjects with heart rates greater than 80 beats/min, minimal motion is usually during end systole. The timing of the subjectspecific image acquisition can be assessed from a cine data set in the 4-chamber view by visual inspection or automated analysis. The length of the mid-diastolic or end-systolic rest period (which typically varies from 50-350 milliseconds) is heart rate-dependent. ${ }^{21}$ Subjects with heart rates greater than 60 beats/min may benefit from $\beta$-blockers to slow their heart rates and to increase their rest period duration. A drawback of imaging within a 50- to 100-millisecond time window per cardiac cycle is that the total imaging time is relatively long. To overcome this drawback, one may use a longer cardiac acquisition window with intra-R-R interval motion correction. $^{22}$ Combining the motion-corrected segments produced a high-resolution image (Figure 1). ${ }^{22}$

\section{RESPIRATORY MOTION COMPENSATION}

Normal diaphragmatic excursion (10-20 mm) may exceed a multiple of the coronary vessel wall thickness $(0.5-2 \mathrm{~mm}){ }^{23}$ Thus respiratory motion compensation is critical for coronary vessel wall imaging.

Initial approaches for visualizing cross sections of the proximal coronary vessel wall used 2-dimensional (2D) breath-hold techniques with mid-diastolic image acquisition. ${ }^{24}$ This approach has variable image quality because many patients cannot hold their breath for the required 15- to 20-second time period. Furthermore, the limited spatial coverage of $2 \mathrm{D}$ techniques limits the clinical potential because evaluation of the entire proximal coronary vessel wall is likely to be important.

To compensate for respiratory motion during a free-breathing examination, a 2D-selective pencil beam navigator placed on the right hemidiaphragm can be used to monitor respiration and to perform real-time gating and slice tracking. ${ }^{19}$ The use of navigator echoes that record and correct for diaphragmatic motion ${ }^{25}$ allows for free-breathing and removes the time constraints of the breath-hold approach, thereby allowing for submillimeter spatial resolution. ${ }^{26,27}$ Similar to coronary MRI, coronary vessel wall imaging can be combined with the navigator technique and can be extended to 3D acquisitions providing a higher signal-to-noise ratio and improved vessel coverage. ${ }^{28}$ The major drawbacks of freebreathing coronary MRI with respiratory navigator gating are low navigator efficiency and prolonged scan time as a result of irregular breathing patterns. A novel technique has been presented, which enables the calibration of a $3 \mathrm{D}$ affine respiratory motion model to the individual motion pattern of the patient. ${ }^{29}$ Preliminary 
Table 2. Markers of vulnerability at plaque level. Modified from Naghavi ${ }^{5}$

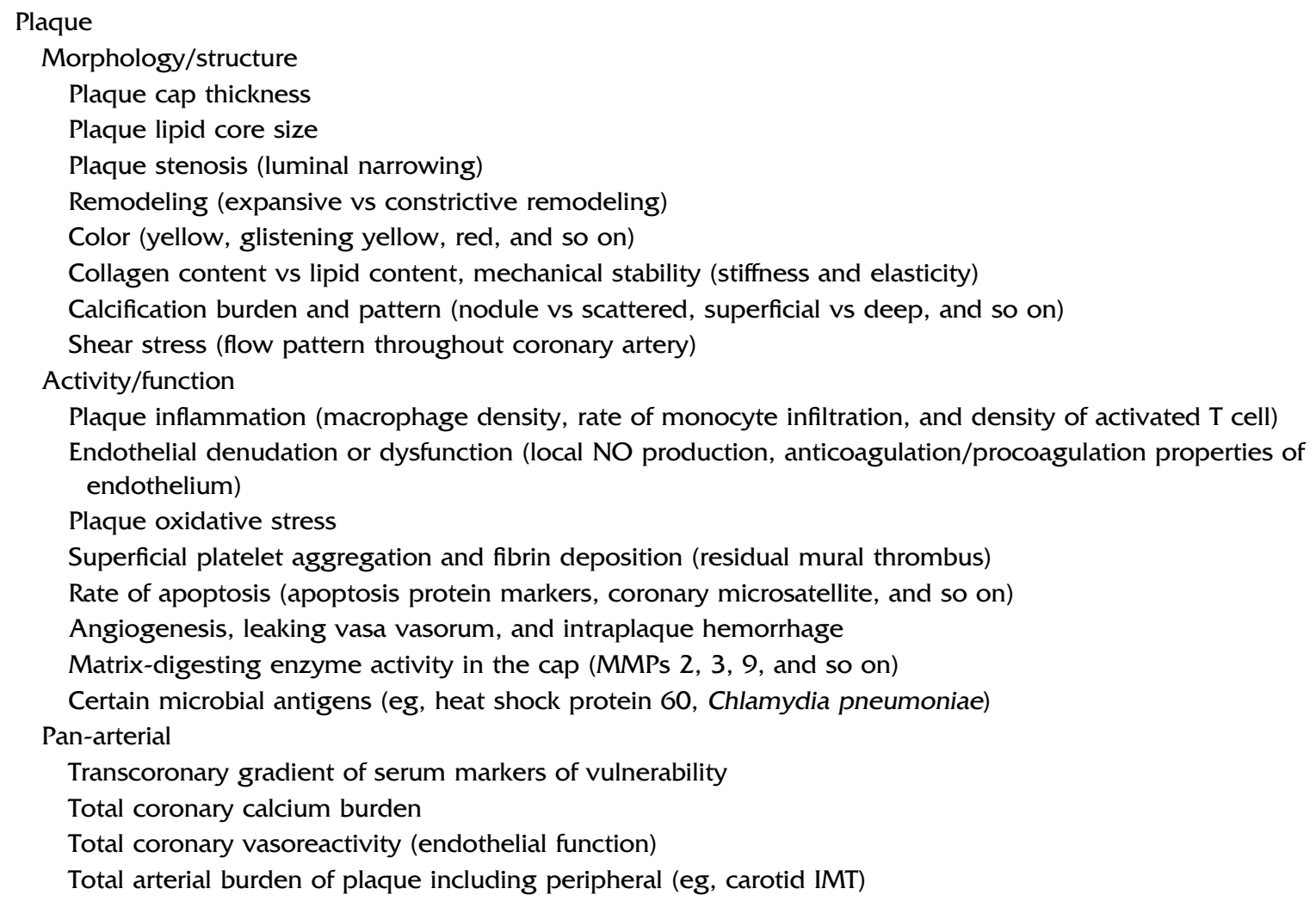

Modified from Naghavi et al. ${ }^{5} M M P$, Matrix metalloproteinase; NO, nitric oxide; IMT, intima medial thickness.

results have shown that this approach increases the scan efficiency without sacrificing image quality and has the potential to be more robust for routine clinical usage. ${ }^{29}$

\section{CORONARY PLAQUE BURDEN}

Early in vivo coronary vessel wall imaging studies used a 2D fat-suppressed fast spin echo technique. ${ }^{24,30}$ Coronary blood signal was suppressed by use of a double inversion pulse, ${ }^{31}$ leading to optimal contrast between lumen and vessel wall. This "black-blood" approach has been implemented in both a 2D breath-hold mode $^{24}$ and a free-breathing mode ${ }^{30}$ and allows for visualization of cross-sectional images of the left anterior descending artery and right coronary artery vessel wall both in healthy subjects and in patients with CAD. In-plane spatial resolution of these first implementations varied from $0.46 \times 0.46 \mathrm{~mm}$ to $0.5 \times 1 \mathrm{~mm}$, with a typical slice thickness of 3 to $5 \mathrm{~mm}$. Wall thickness was found to be higher in patients with CAD when compared with normal healthy subjects. ${ }^{24,30}$

Because of the highly tortuous path of the coronary artery system, cross-sectional vessel wall imaging of the coronary arteries is time-inefficient, therefore making a vessel-targeted approach more desirable. Such an approach was implemented via a 3-point plan scan method $^{32}$ and combined with a modified black-blood prepulse (local inversion) ${ }^{28}$ which allows acquisition of 3D stacks along the major axis of the coronary artery system. This novel technique allowed for visualization of the proximal and mid portions of the right coronary artery and left anterior descending artery wall with good contrast between coronary blood and the vessel wall. ${ }^{28}$ Free-breathing 3D black-blood coronary CMR identified an increased coronary vessel wall thickness with preservation of lumen size in patients with nonsignificant CAD, consistent with a "Glagov-type" outward arterial remodeling (Figure 2). ${ }^{33}$ Acquisition of isotropic voxels, ${ }^{34}$ which facilitates reconstruction of arbitrary views, may prove useful for reconstruction of cross-sectional vessel wall images along a user-defined path from a single 3D data set.

\section{CORONARY ATHEROTHROMBOSIS IMAGING BY CMR}

CMR has shown great promise as a comprehensive imaging modality for in vivo imaging of atherothrombo- 

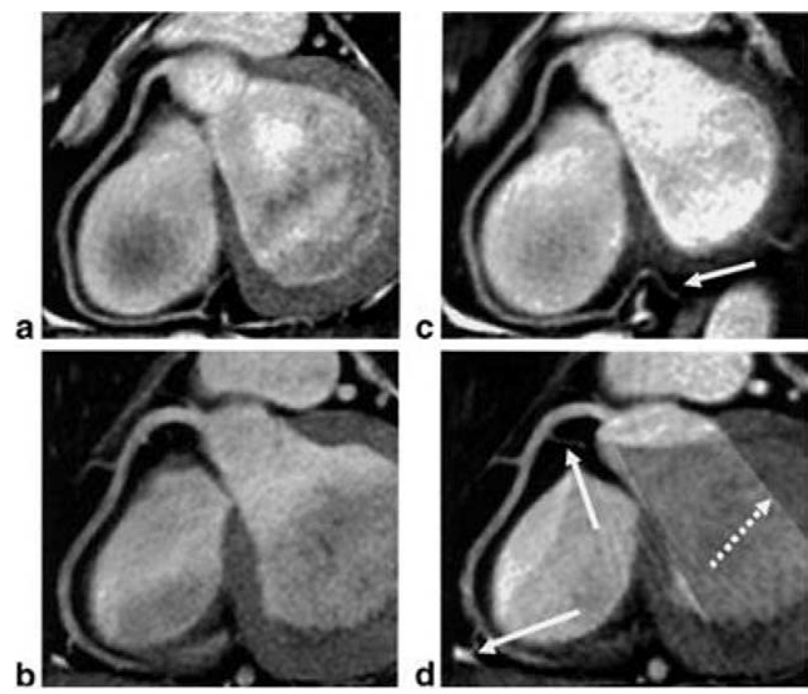

Figure 1. Reformatted coronary MR images of the right coronary artery obtained by the conventional protocol (A and B) and by the novel sequence comprising high scan efficiency and intra-R-R interval motion correction ( $\mathbf{C}$ and $\mathbf{D})$. Higher signal-to-noise ratio and contrast-to-noise ratio are evident in the motion-corrected images. Also, more details such as small distal branches could be reconstructed by use of motioncorrected scanning (solid arrows). Some artifacts resulting from the retrospective correction may occur, as regions may comprise image data from a subset of the acquired segments only (dashed arrow). However, these effects do not occur within the region of interest, such as the coronary vessel. (Reproduced with permission from reference 22.)

sis. Multispectral MRI relies on the fact that the magnetic resonance (MR) signal emitted by water protons $\left({ }^{1} \mathrm{H}\right)$ varies according to their molecular environment. In principle, each plaque component has an MR-specific "ZIP code," which is composed of the $\mathrm{T}_{1}$ and $\mathrm{T}_{2}$ relaxation times, proton density, molecular diffusion, magnetization transfer, and so on. ${ }^{35}$ Because there is an overlap of signal intensities between the different sequences and the different plaque components, unique identification of plaque components can be difficult. Nevertheless, multispectral MRI has been successfully demonstrated for plaque characterization in ex vivo vessel specimens, ${ }^{35-37}$ in experimental animals, ${ }^{17,38,39}$ and in human carotid artery ${ }^{18,40}$ and aorta $^{41,42}$ in vivo. Currently, spatial resolution remains the limiting factor for detailed coronary plaque characterization. On the basis of simulations and phantom studies, it was demonstrated that at least 1 pixel is needed across the different tissue layers of the vessel wall (fibrous cap, lipid pool, smooth muscle) to characterize different vessel wall components reliably. ${ }^{43}$ Furthermore, respiratory motion correction needs to be as accurate as 3 times the thickness of the tissue layer. ${ }^{43}$ In principle, these boundaries could be met with the current navigator-based 3D

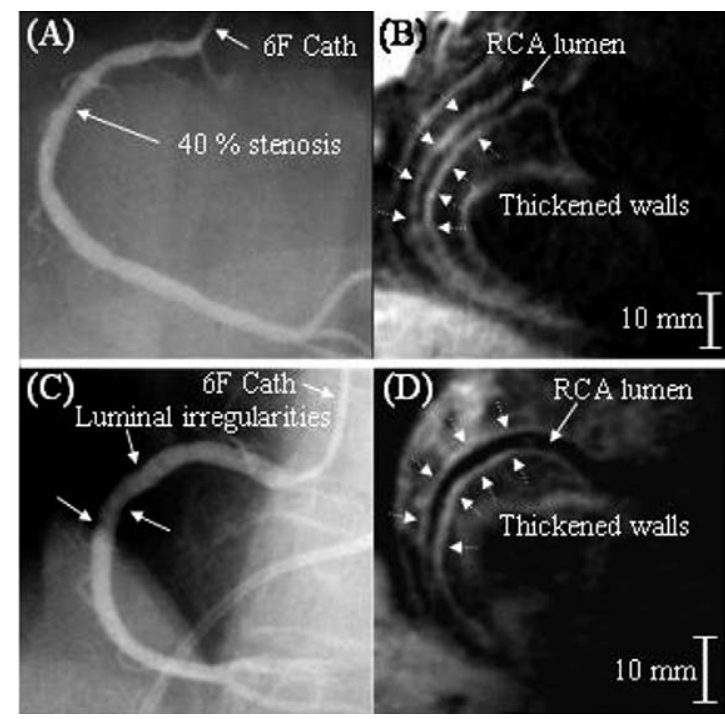

Figure 2. X-ray angiography in 2 patients with a focal $40 \%$ stenosis (white arrow) (A) and minor (approximately 10\% stenoses) luminal irregularities (white arrows) (C) of the proximal right coronary artery. The corresponding black-blood 3D cardiovascular magnetic resonance vessel wall scans (B and D) demonstrate the irregularly thickened right coronary artery wall $(>2 \mathrm{~mm})$ indicative of an increased atherosclerotic plaque burden. The inner and outer walls are indicated by the black dotted arrows. (Reproduced with permission from reference 33.)

coronary vessel wall sequences. ${ }^{28,33}$ However, from a practical perspective, high-resolution imaging causes a reduction in the signal-to-noise ratio. Therefore the use of exogenous targeted contrast agents, ${ }^{44,45}$ intravascular coils, ${ }^{46}$ and higher magnetic field strengths ${ }^{47}$ may be required for detailed vessel wall imaging. Different MR probes have been developed to study various biologic processes (eg, thrombosis, angiogenesis, inflammation, and neoplasia) and diseases (eg, cancer, cardiovascular disease, stroke, and diabetes) by targeting a spectrum of molecular markers such as fibrin, selectins, and integrins. Most of these agents are in the preclinical stage.

Recently, advances have been made with in vivo imaging of arterial thrombus by fibrin-binding molecular MR contrast agents. ${ }^{44,45}$ Direct imaging of arterial thrombus by targeted or "molecular" contrast agents (which are engineered to bind to specific target molecules) is advantageous to classical noncontrast multispectral MRI because the demand for high spatial resolution and motion compensation strategies is less stringent. Furthermore, even though several studies have shown high sensitivity of MRI in the detection of carotid and aortic thrombi ${ }^{48-50}$ differentiation between complex atherosclerotic plaques and mural thrombosis remains difficult because of the complex composition (eg, platelets, fibrin, and red blood cells) of thrombus and resultant 


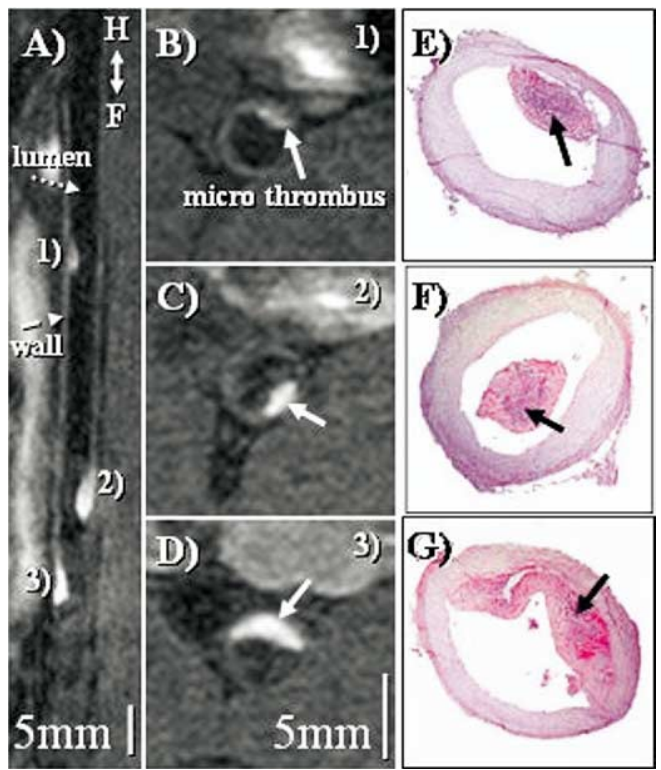

Figure 3. A, Reformatted coronary MR image from coronal 3D data set shows subrenal aorta 20 hours after EP-1873 administration in a rabbit model of atherosclerosis and plaque rupture. Three well-delineated mural thrombi (arrows) can be observed, with good contrast between thrombus (numbered), arterial blood (dotted arrow), and vessel wall (dashed arrow). The in-plane view of the aorta allows simultaneous display of all thrombi, showing head, tail, length, and relative location. B, C, and $\mathbf{D}$, Corresponding cross-sectional views show good agreement with histopathology $(\mathbf{E}, \mathbf{F}$, and $\mathbf{G})$. (Reproduced with permission from reference 44.)

complex MR signal characteristics on $\mathrm{T}_{1^{-}}, \mathrm{T}_{2^{-}}$, and proton density-weighted images of arterial thrombi. The concept of targeted imaging was first introduced over a decade ago and has since been further developed by Weissleder and colleagues ${ }^{51-53}$ for MRI and optical imaging in recent years. The advantage of CMR molecular plaque imaging is the potential for relatively high spatial resolution. The limitation is the inherently low sensitivity of MR contrast enhancement technology, requiring a relatively high target molecule concentration (>50-100 $\mu \mathrm{mol} / \mathrm{L}$ gadolinium at target site) for sufficient signal amplification. Initial attempts were made with targeting fibrin, ${ }^{54-56}$ which is abundant in arterial clots and plays an important role in acute coronary syndromes and stroke. In vivo MRI of acute and subacute thrombosis after plaque rupture in an animal model of aortic atherosclerosis has been implemented by use of a small-molecule fibrin-binding peptide derivative, EP1873 (EPIX Pharmaceuticals Inc, Cambridge, Mass) (Figure 3). ${ }^{44}$ This novel molecular agent allowed for imaging of large lumen encroaching thrombi as well as submillimeter mural thrombi with signal enhancement of the entire thrombus and excellent differentiation from the vessel wall. Combining the advent of fibrin-binding molecular MR contrast agents and advances in coronary MRI techniques offers the potential for direct imaging of coronary thrombosis. The feasibility of this approach was demonstrated by use of a gadolinium-based fibrinbinding contrast agent, EP-2104R (EPIX Pharmaceuticals Inc), in a swine model of native coronary thrombus (Figure 4) and in-stent thrombosis by use of MR-lucent stents (Figure 5). ${ }^{45}$ Potential applications for direct thrombus imaging include detection and evaluation of acute coronary syndromes and ischemic strokes.

Integrins, such as $\alpha_{\mathrm{v}} \beta_{3}$, are associated with angiogenesis, which is a critical feature of plaque development in atherosclerosis, and likely play a key role in plaque rupture leading to myocardial infarction or stroke. Increased angiogenesis is detected as signal enhancement in the MR signal averaged throughout the abdominal aortic wall among hyperlipidemic rabbits that receive $\alpha_{v} \beta_{3}$-targeted, paramagnetic nanoparticles. ${ }^{57}$ Histology and immunohistochemistry confirm marked proliferation of angiogenic vessels within the aortic adventitia among cholesterol-fed, atherosclerotic rabbits in comparison with a sparse incidence of neovasculature in control animals.

Vascular inflammation and associated endothelial activation are believed to play an integral role in the initiation and progression of atherosclerosis. Endothelial cells express adhesion molecules such as E- and Pselectin, which facilitate adhesion and migration of monocytes. Differentiation of monocytes into macrophages and subsequent digestion of lipoproteins by macrophages occur in a later stage and eventually lead to the accumulation of lipid-filled macrophages, which are believed to be a precursor of rupture-prone vulnerable plaque. Early endothelial activation has been detected by use of a novel MR contrast agent in rats with brain inflammation (after interleukin-1 $\beta$ - and tumor necrosis factor $\alpha$-induced E- and P-selectin upregulation $)^{58}$ and in focal ischemia in mice brains. ${ }^{59}$ This novel gadoliniumlabeled contrast agent, gadolinium-diethylenetriamine pentaacetic acid-B(sLe $\left.{ }^{\mathrm{x}}\right) \mathrm{A},{ }^{60}$ consists of the Sialyl Lewis ${ }^{\mathrm{x}}$ $\left(\mathrm{sLe}^{\mathrm{x}}\right)$ carbohydrate, which interacts with both E- and P-selectin. These promising results encourage further studies including assessment of E- and P-selectin upregulation in early atherosclerotic lesions in the coronary arteries.

\section{SUMMARY}

Atherothrombosis, defined as atherosclerotic lesion disruption with superimposed thrombus formation, is the major cause of acute coronary syndromes and cardiovascular death. CMR imaging of coronary atherothrombosis is challenging because of the small caliber of the vessels combined with respiratory and cardiac motion. Freebreathing 3D CMR coronary vessel wall imaging has 


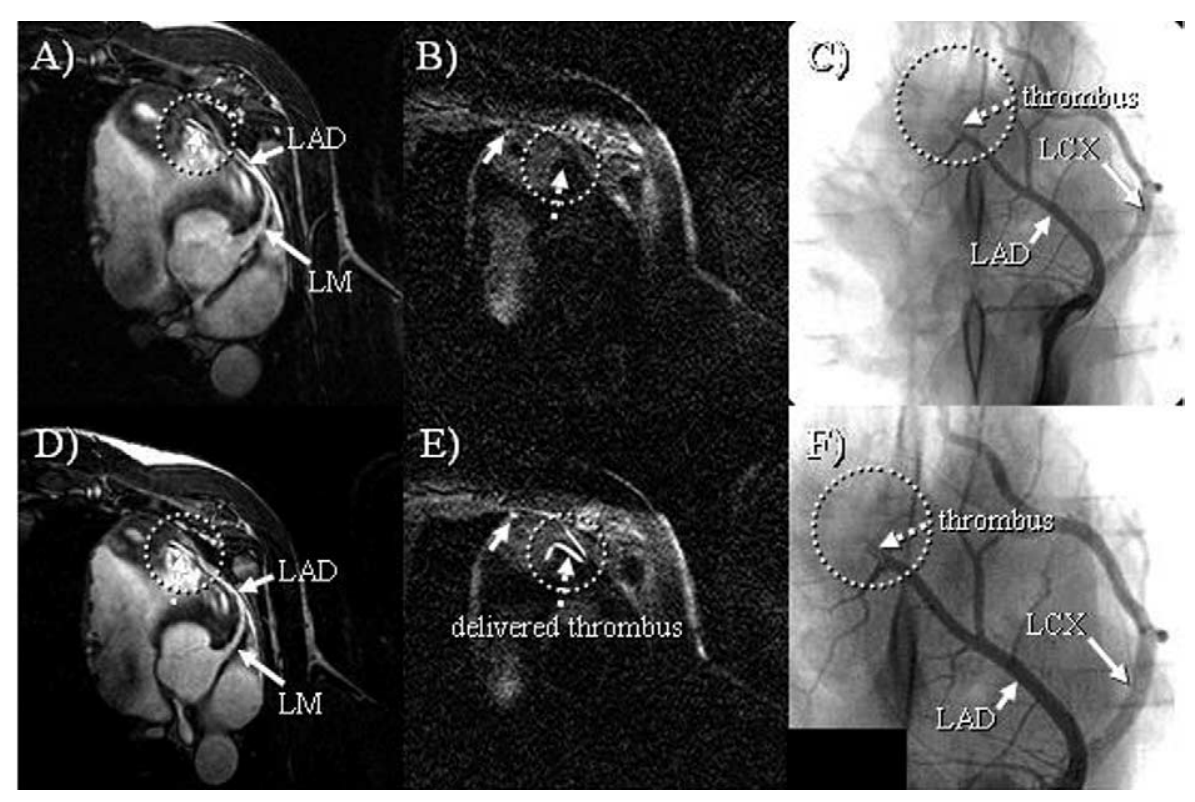

Figure 4. In vivo MR image of gadolinium-labeled fibrinogen clots. Coronary MR images before (A) and after (D) thrombus delivery. On both scans, no apparent thrombus is visible (circle). Black-blood inversion recovery turbo field echo scans (MR thrombus imaging) before (B) and after (E) clot delivery (same view as $\mathbf{A}$ and $\mathbf{D}$ ) are shown. After thrombus delivery (E), 3 bright areas are readily visible (arrows and circle), consistent with the location of thrombus. No apparent thrombus was visible on prethrombus images (B) (arrow and circle). C, X-ray angiogram confirming MRI finding of thrombus in mid left anterior descending artery $(L A D)$ (circle). F, Magnified view of $\mathbf{C}$. $L M$, Left main artery; $L A D$, left anterior descending artery; $L C X$, left circumflex coronary artery. (Reproduced with permission from reference 45.)

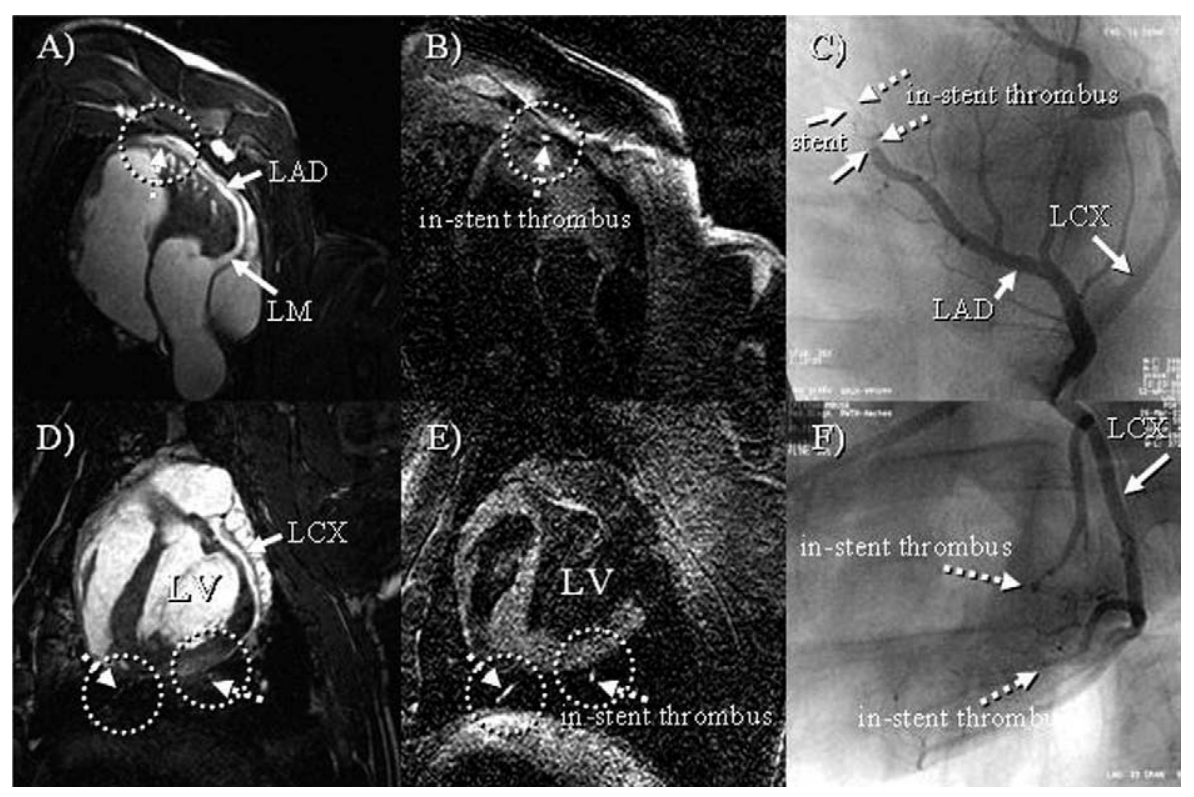

Figure 5. In-vivo MR molecular imaging of coronary in-stent thrombosis. A, Bright blood steady-state free precession images (coronary lumen MRI) of LM/LAD after stent placement and injection of EP-2104R. No apparent thrombus and no stent artifacts are visible on the post-stent placement and EP-2104R bright blood images. B, MR thrombus imaging after stent placement and EP-2104R. A bright spot (arrow) is visible after intracoronary injection of EP-2104R. C, Thrombus was subsequently confirmed by $\mathrm{x}$-ray angiography. D, Bright blood image after LCX stent placement and EP-2104R. No apparent thrombus is visible. E, MR thrombus imaging after stent placement and EP-2104R demonstrating 2 thrombi in the mid LCX (arrows). F, X-ray coronary angiogram confirming MR findings. (Reproduced with permission ${ }^{45}$ ) 
enabled in vivo quantification of coronary plaque burden and remodeling as a marker of subclinical CAD. Molecular imaging via novel target-specific contrast agents such as fibrin-binding agents to detect arterial thrombus shows great promise as the new frontier in noninvasive imaging. Advances in molecular imaging and CMR techniques offer the potential for direct imaging of coronary thrombosis and in-stent thrombosis by use of novel fibrin-binding molecular MR contrast agents. Although the current role of noninvasive CMR imaging of atherothrombosis remains investigational, these techniques should enhance our understanding of the natural history of acute coronary syndromes and thereby facilitate strategies to prevent acute coronary syndromes and cardiovascular death in vulnerable patients.

\section{Acknowledgment}

Dr Manning receives research grant support from Philips Medical Systems and EPIX Pharmaceuticals, Inc. He is also a consultant to EPIX Pharmaceuticals, Inc. Drs Botnar and Spuentrup have received research funding from EPIX Pharmaceuticals, Inc. Drs Kim and Bucker have indicated they have no financial conflicts of interest.

\section{REFERENCES}

1. Yusuf S, Reddy S, Ounpuu S, Anand S. Global burden of cardiovascular diseases: part I: general considerations, the epidemiologic transition, risk factors, and impact of urbanization. Circulation 2001;104:2746-53.

2. Virmani R, Kolodgie FD, Burke AP, Farb A, Schwartz SM. Lessons from sudden coronary death: a comprehensive morphological classification scheme for atherosclerotic lesions. Arterioscler Thromb Vasc Biol 2000;20:1262-75.

3. Falk E, Shah PK, Fuster V. Coronary plaque disruption. Circulation 1995;92:657-71.

4. Davies MJ. A macro and micro view of coronary vascular insult in ischemic heart disease. Circulation 1990;II38-46.82(Suppl II):

5. Naghavi M, Libby P, Falk E, Casscells SW, Litovsky S, Rumberger J, et al. From vulnerable plaque to vulnerable patient: a call for new definitions and risk assessment strategies, part I. Circulation 2003;108:1664-72.

6. Mann J, Davies MJ. Mechanisms of progression in native coronary artery disease: role of healed plaque disruption. Heart 1999;82: 265-8.

7. Burke AP, Farb A, Malcom GT, Liang YH, Smialek J, Virmani R. Coronary risk factors and plaque morphology in men with coronary disease who died suddenly. N Engl J Med 1997;336:1276-82.

8. Goldstein JA, Demetriou D, Grines CL, Pica M, Shoukfeh M, O'Neill WW. Multiple complex coronary plaques in patients with acute myocardial infarction. N Engl J Med 2000;343:915-22.

9. Nissen SE. Who is at risk for atherosclerotic disease? Lessons from intravascular ultrasound Am J Med 2002;112(Suppl 8A):27S-33S.

10. Rioufol G, Finet G, Ginon I, Andre-Fouet X, Rossi R, Vialle E, et al. Multiple atherosclerotic plaque rupture in acute coronary syndrome: a three-vessel intravascular ultrasound study. Circulation $2002 ; 106: 804-8$.
11. Buffon A, Biasucci LM, Liuzzo G, D’Onofrio G, Crea F, Maseri A. Widespread coronary inflammation in unstable angina. N Engl J Med 2002;347:5-12.

12. Casscells W, Naghavi M, Willerson JT. Vulnerable atherosclerotic plaque: a multifocal disease. Circulation 2003;107:2072-5.

13. Maseri A, Fuster V. Is there a vulnerable plaque? Circulation 2003;107:2068-71.

14. Kereiakes DJ. The emperor's clothes: in search of the vulnerable plaque. Circulation 2003;107:2076-7.

15. Abela GS, Eisenberg JD, Mittleman MA, Nesto RW, Leeman D, Zarich $\mathrm{S}$, et al. Detecting and differentiating white from red coronary thrombus by angiography in angina pectoris and in acute myocardial infarction. Am J Cardiol 1999;83:94-7.

16. Toussaint JF, LaMuraglia GM, Southern JF, Fuster V, Kantor HL. Magnetic resonance images lipid, fibrous, calcified, hemorrhagic, and thrombotic components of human atherosclerosis in vivo. Circulation 1996;94:932-8.

17. Fayad ZA, Fallon JT, Shinnar M, Wehrli S, Dansky HM, Poon M, et al. Noninvasive In vivo high-resolution magnetic resonance imaging of atherosclerotic lesions in genetically engineered mice. Circulation 1998;98:1541-7.

18. Yuan C, Mitsumori LM, Ferguson MS, Polissar NL, Echelard D, Ortiz G, et al. In vivo accuracy of multispectral magnetic resonance imaging for identifying lipid-rich necrotic cores and intraplaque hemorrhage in advanced human carotid plaques. Circulation 2001;104:2051-6.

19. Kim WY, Danias PG, Stuber M, Flamm SD, Plein S, Nagel E, et al. Coronary magnetic resonance angiography for the detection of coronary stenoses. N Engl J Med 2001;345:1863-9.

20. Wang Y, Vidan E, Bergman GW. Cardiac motion of coronary arteries: variability in the rest period and implications for coronary MR angiography. Radiology 1999;213:751-8.

21. Kim WY, Stuber M, Kissinger KV, Andersen NT, Manning WJ, Botnar RM. Impact of bulk cardiac motion on right coronary MR angiography and vessel wall imaging. J Magn Reson Imaging 2001; 14:383-90.

22. Stehning C, Bornert P, Nehrke K, Dossel O. Free breathing 3D balanced FFE coronary magnetic resonance angiography with prolonged cardiac acquisition windows and intra-RR motion correction. Magn Reson Med 2005;53:719-23.

23. Taylor AM, Jhooti P, Wiesmann F, Keegan J, Firmin DN, Pennell DJ. MR navigator-echo monitoring of temporal changes in diaphragm position: implications for MR coronary angiography. J Magn Reson Imaging 1997;7:629-36.

24. Fayad ZA, Fuster V, Fallon JT, Jayasundera T, Worthley SG, Helft $\mathrm{G}$, et al. Noninvasive in vivo human coronary artery lumen and wall imaging using black-blood magnetic resonance imaging. Circulation 2000;102:506-10.

25. Ehman RL, Felmlee JP. Adaptive technique for high-definition MR imaging of moving structures. Radiology 1989;173:25563.

26. Li D, Kaushikkar S, Haacke EM, Woodard PK, Dhawale PJ, Kroeker RM, et al. Coronary arteries: three-dimensional MR imaging with retrospective respiratory gating. Radiology 1996; 201:857-63.

27. Stuber M, Botnar RM, Danias PG, Kissinger KV, Manning WJ. Submillimeter three-dimensional coronary MR angiography with real-time navigator correction: comparison of navigator locations. Radiology 1999;212:579-87.

28. Botnar RM, Kim WY, Bornert P, Stuber M, Spuentrup E, Manning WJ. 3D coronary vessel wall imaging utilizing a local inversion technique with spiral image acquisition. Magn Reson Med 2001; 46:848-54. 
29. Manke D, Nehrke K, Bornert P. Novel prospective respiratory motion correction approach for free-breathing coronary MR angiography using a patient-adapted affine motion model. Magn Reson Med 2003;50:122-31.

30. Botnar RM, Stuber M, Kissinger KV, Kim WY, Spuentrup E, Manning WJ. Noninvasive coronary vessel wall and plaque imaging with magnetic resonance imaging. Circulation 2000;102:2582-7.

31. Edelman RR, Chien D, Kim D. Fast selective black blood MR imaging. Radiology 1991;181:655-60.

32. Stuber M, Botnar RM, Danias PG, Sodickson DK, Kissinger KV, Van Cauteren M, et al. Double-oblique free-breathing high resolution three-dimensional coronary magnetic resonance angiography. J Am Coll Cardiol 1999;34:524-31.

33. Kim WY, Stuber M, Bornert P, Kissinger KV, Manning WJ, Botnar RM. Three-dimensional black-blood cardiac magnetic resonance coronary vessel wall imaging detects positive arterial remodeling in patients with nonsignificant coronary artery disease. Circulation 2002;106:296-9.

34. Botnar RM, Stuber M, Kissinger KV, Manning WJ. Free-breathing 3D coronary MRA: the impact of "isotropic" image resolution. J Magn Reson 2000;11:389-93.

35. Shinnar M, Fallon JT, Wehrli S, Levin M, Dalmacy D, Fayad ZA, et al. The diagnostic accuracy of ex vivo MRI for human atherosclerotic plaque characterization. Arterioscler Thromb Vasc Biol 1999;19:2756-61.

36. Yuan C, Petty C, O'Brien KD, Hatsukami TS, Eary JF, Brown BG. In vitro and in situ magnetic resonance imaging signal features of atherosclerotic plaque-associated lipids. Arterioscler Thromb Vasc Biol 1997; 17:1496-503.

37. Rogers WJ, Prichard JW, Hu YL, Olson PR, Benckart DH, Kramer $\mathrm{CM}$, et al. Characterization of signal properties in atherosclerotic plaque components by intravascular MRI. Arterioscler Thromb Vasc Biol 2000;20:1824-30.

38. Yuan C, Skinner MP, Kaneko E, Mitsumori LM, Hayes CE, Raines EW, et al. Magnetic resonance imaging to study lesions of atherosclerosis in the hyperlipidemic rabbit aorta. Magn Reson Imaging 1996;14:93-102.

39. Worthley SG, Helft G, Fuster V, Fayad ZA, Rodriguez OJ, Zaman AG, et al. Noninvasive in vivo magnetic resonance imaging of experimental coronary artery lesions in a porcine model. Circulation 2000;101:2956-61.

40. Cai JM, Hatsukami TS, Ferguson MS, Small R, Polissar NL, Yuan C. Classification of human carotid atherosclerotic lesions with in vivo multicontrast magnetic resonance imaging. Circulation 2002; 106:1368-73.

41. Fayad ZA, Nahar T, Fallon JT, Goldman M, Aguinaldo JG, Badimon JJ, et al. In vivo magnetic resonance evaluation of atherosclerotic plaques in the human thoracic aorta: a comparison with transesophageal echocardiography. Circulation 2000;101: 2503-9.

42. Jaffer FA, O'Donnell CJ, Larson MG, Chan SK, Kissinger KV, Kupka MJ, et al. Age and sex distribution of subclinical aortic atherosclerosis: a magnetic resonance imaging examination of the Framingham Heart Study. Arterioscler Thromb Vasc Biol 2002; 22:849-54.

43. Schar M, Kim WY, Stuber M, Boesiger P, Manning WJ, Botnar $\mathrm{RM}$. The impact of spatial resolution and respiratory motion on MR imaging of atherosclerotic plaque. J Magn Reson Imaging 2003; $17: 538-44$.
44. Botnar RM, Perez AS, Witte S, Wiethoff AJ, Laredo J, Hamilton $\mathrm{J}$, et al. In vivo molecular imaging of acute and subacute thrombosis using a fibrin-binding magnetic resonance imaging contrast agent. Circulation 2004;109:2023-9.

45. Botnar RM, Buecker A, Wiethoff AJ, Parsons EC Jr, Katoh M, Katsimaglis $G$, et al. In vivo magnetic resonance imaging of coronary thrombosis using a fibrin-binding molecular magnetic resonance contrast agent. Circulation 2004;110:1463-6.

46. Botnar RM, Bucker A, Kim WY, Viohl I, Gunther RW, Spuentrup E. Initial experiences with in vivo intravascular coronary vessel wall imaging. J Magn Reson Imaging 2003;17:615-9.

47. Botnar RM, Stuber M, Lamerichs R, Smink J, Fischer SE, Harvey $\mathrm{P}$, et al. Initial experiences with in vivo right coronary artery human MR vessel wall imaging at 3 tesla. J Cardiovasc Magn Reson 2003;5:589-94.

48. Johnstone MT, Botnar RM, Perez AS, Stewart R, Quist WC, Hamilton JA, et al. In vivo magnetic resonance imaging of experimental thrombosis in a rabbit model. Arterioscler Thromb Vasc Biol 2001;21:1556-60.

49. Corti R, Osende JI, Fayad ZA, Fallon JT, Fuster V, Mizsei G, et al In vivo noninvasive detection and age definition of arterial thrombus by MRI. J Am Coll Cardiol 2002;39:1366-73.

50. Moody AR, Murphy RE, Morgan PS, Martel AL, Delay GS, Allder $\mathrm{S}$, et al. Characterization of complicated carotid plaque with magnetic resonance direct thrombus imaging in patients with cerebral ischemia. Circulation 2003;107:3047-52.

51. Weissleder R, Elizondo G, Wittenberg J, Rabito CA, Bengele HH, Josephson L. Ultrasmall superparamagnetic iron oxide: characterization of a new class of contrast agents for MR imaging. Radiology 1990;175:489-93.

52. Weissleder R. Molecular imaging: exploring the next frontier. Radiology 1999;212:609-14.

53. Weissleder R, Ntziachristos V. Shedding light onto live molecular targets. Nat Med 2003;9:123-8.

54. Johansson LO, Bjornerud A, Ahlstrom HK, Ladd DL, Fujii DK. A targeted contrast agent for magnetic resonance imaging of thrombus: implications of spatial resolution. J Magn Reson Imaging 2001;13:615-8.

55. Flacke S, Fischer S, Scott MJ, Fuhrhop RJ, Allen JS, McLean M, et al. Novel MRI contrast agent for molecular imaging of fibrin: implications for detecting vulnerable plaques. Circulation 2001; 104:1280-5.

56. Yu X, Song SK, Chen J, Scott MJ, Fuhrhop RJ, Hall CS, et al. High-resolution MRI characterization of human thrombus using a novel fibrin-targeted paramagnetic nanoparticle contrast agent. Magn Reson Med 2000;44:867-72.

57. Winter PM, Morawski AM, Caruthers SD, Fuhrhop RW, Zhang H, Williams TA, et al. Molecular imaging of angiogenesis in earlystage atherosclerosis with alpha(v)beta3-integrin-targeted nanoparticles. Circulation 2003;108:2270-4.

58. Sibson NR, Blamire AM, Bernades-Silva M, Laurent S, Boutry S, Muller RN, et al. MRI detection of early endothelial activation in brain inflammation. Magn Reson Med 2004;51:248-52.

59. Barber PA, Foniok T, Kirk D, Buchan AM, Laurent S, Boutry S, et al. MR molecular imaging of early endothelial activation in focal ischemia. Ann Neurol 2004;56:116-20.

60. Laurent S, Vander Elst L, Fu Y, Muller RN. Synthesis and physicochemical characterization of Gd-DTPA-B(sLex)A, a new MRI contrast agent targeted to inflammation. Bioconjug Chem 2004;15:99-103. 